\title{
NOTICE AND TAKEDOWN: ONLINE SERVICE PROVIDER AND RIGHTSHOLDER ACCOUNTS OF EVERYDAY PRACTICE
}

\author{
by Jennifer M. Urban, Joe Karaganis, \\ AND BRianna L. SChOfIElD*
}

\begin{abstract}
Section 512 of the Digital Millennium Copyright Act established both "safe harbors" from liability for online service providers and the well-known "no-
\end{abstract}

*Jennifer M. Urban is a Clinical Professor of Law at the University of California, Berkeley School of Law and Director of the Samuelson Law, Technology \& Public Policy Clinic. Brianna L. Schofield is the Executive Director of Authors Alliance and former Clinical Teaching Fellow at the Samuelson Law, Technology \& Public Policy Clinic at the University of California, Berkeley School of Law. Joe Karaganis is Vice President at The American Assembly at Columbia University. This is a digested and updated version of a portion of the longer research report, Notice and Takedown in Everyday Practice. A digested version of the two other studies in Notice and Takedown in Everyday Practice is forthcoming in the fall issue of the Journal of the Copyright Society of the USA. This research is a part of the Takedown Project, a collaborative effort led by Urban and Karaganis to develop a global network of researchers studying notice and takedown procedures in order to advance understanding of how these procedures resolve copyright and other conflicts and how they mediate freedom of expression online. More information can be found on the project's website, https://takedownproject.org.

We are deeply grateful to our survey respondents and interviewees for generously contributing their time and expertise, and for candidly sharing their "on the ground" experiences with notice and takedown. We are grateful for funding support from Google Inc. as a gift to The American Assembly and from the Sloan Foundation for its support through the Berkeley Law Digital Library Copyright Project. Neither funder directed our approach in any way, and neither funder reviewed any methods, data, results, or reporting before public release.

We are indebted to the individuals who have generously lent their time, skill, and expertise to this project. For his excellent work on the development and management of this study, we thank Kristoff Grospe. For their detailed and helpful comments on study design, findings, and report drafts, we thank Annemarie Bridy, Niva Elkin-Koren, Gwen Hinze, Martin Husovec, Deirdre Mulligan, Bill Rosenblatt, and participants in multiple Takedown Project workshops, the 3rd Global Congress on Intellectual Property Rights and the Public Interest, the 4th Global Congress on Intellectual Property Rights and the Public Interest, the 18th Annual Berkeley Center for Law and Technology and Berkeley Technology Law Journal Symposium "The Next Great Copyright Act," the Department of Commerce Multistakeholder Forum on Improving the Operation of the DMCA Notice and Takedown System, the Chicago-Kent College of Law's Conference on Empirical Research on Copyright Issues, and the Copyright Society of the USA's Copyright and Technology Conference. Lydia Anderson-Dana provided excellent research assistance in the final stages of the project. Mistakes are ours alone. 


\begin{tabular}{lllll}
\hline |ljciprod01 $\mid$ productn $\backslash \mathrm{C} \backslash \mathrm{CPY} \backslash$ 64-3\CPY303.txt & unknown & Seq: 2 & 28-SEP-17 & 12:42 \\
\hline
\end{tabular}

tice and takedown" process for removing online infringements of copyrighted material. In the ensuing two decades, the notice and takedown process has become a primary tool for raising and resolving copyright disputes in the United States.

But despite its influence, there is little empirical research describing $\$ 512$ 's operation or its effectiveness. This article digests findings from a qualitative study, reported fully in the three-study report, Notice and Takedown in Everyday Practice, ${ }^{1}$ that helps fill this gap. Through detailed surveys and interviews with nearly three dozen respondents, we provide the first detailed account of how $\$ 512$ is implemented and experienced by online service providers and large rightsholders. All respondents agreed that the $\$ 512$ safe harbors and the ability to take down infringing material remain fundamental. But the online copyright enforcement ecosystem is also highly diverse, and all participants face challenges. The findings suggest that the notice and takedown system is important, under strain, and that there is no "one size fits all" approach to improving it. Based on the findings, we suggest a variety of best practices and limited legal reforms.

\section{TABLE OF CONTENTS}

I. INTRODUCTION ............................ 373

II. SUMMARY OF METHODS ................... 376

III. OSP AND RIGHTSHOLDER ACCOUNTS OF NOTICE AND TAKEDOWN PRACTICE ................. 378

A. "Woven Into the Fabric" of the Internet .......... 378

B. Diversity In Practice: "DMCA Classic," "DMCA Auto," and "DMCA Plus"..................... 379

C. Everyday Practice: Implementing Notice and Takedown and Managing Challenges..................... 384

1. Identifying and Removing Infringing Content .... 384

2. Avoiding and Managing Flawed Notices......... 385

3. Substantive Mistakes and Human-Sent Notices .... 389

4. Flawed Notices and Risk Aversion ............ 389

5. Counter Notices: Inadequate and Infrequently Used ................................ 393

D. Targeting Search Services to Make Infringing Material "A Little Bit Harder to Find" . .................... 394

E. Compliance, Competition, and Market Power ....... 397

1. DMCA Classic OSPs Fear Policy or Norm Shifts Towards DMCA Auto and Plus ............. 398

1 For a full description of the three studies, see Jennifer M. Urban, JoE Karaganis \& Brianna L. Schofield, Notice and Takedown in Everyday PracTICE (2016), https://papers.ssrn.com/sol3/papers.cfm?abstract_id=2755628. 


\begin{tabular}{lllll}
\hline |ljciprod01 $\mid$ productn $\backslash \mathrm{C} \backslash \mathrm{CPY} \backslash$ 64-3\CPY303.txt & unknown & Seq: 3 & 28-SEP-17 & 12:42 \\
\hline
\end{tabular}

Notice and Takedown

373

2. DMCA Plus is Viewed as a Competitive

Advantage that Affects Market Entry, Success, and

Political Power............................. 399

IV. DISCUSSION AND RECOMMENDATIONS ......... 402

A. Discussion ............................. 402

B. Recommendations and Future Research .......... 406

V. CONCLUSION ............................... 409

\section{INTRODUCTION}

As its twentieth birthday approaches, $\S 512$ of the Digital Millennium Copyright $\mathrm{Act}^{2}$ ("DMCA") is the subject of controversy. Section 512's creators drafted a compromise intended to balance remedies for copyright holders faced with online infringement, protections and responsibilities for online service providers ("OSPs"), and protections for Internet users. But today, the compromise established by $\S 512$ may be unraveling. The law is at the center of hot disputes between the movie, music, and publishing industries on the one hand, and intermediary OSPs, on the other.

Congress crafted the $\S 512$ compromise to support then-nascent OSP investment and competition while encouraging OSPs and rightsholders to cooperate on copyright enforcement. ${ }^{3}$ To accomplish the first goal, Congress gave OSPs "safe harbors" from certain forms of secondary liability for their users' copyright infringement. To accomplish the second, it required OSPs to implement certain protections for copyright holders, most notably the familiar "notice and takedown" process, by which copyright owners can request that infringing materials be removed from online sites by sending brief "takedown notices" to OSPs, without the expense and hassle of filing a lawsuit. Congress sought to protect Internet users' expression interests by making clear that OSPs had no duty to police their networks proactively and by providing a "counter notice" process by which notice targets can contest notices and request that the OSP replace disputed material.

In the ensuing two decades, however, the Internet has grown and changed in ways Congress could not easily have foreseen when it passed the DMCA. Google launched in 1998, the year $\$ 512$ was passed. Napster followed in 1999, then other peer-to-peer networks, a technology model not anticipated by the DMCA. Later still, Facebook and other social networks, along with YouTube and other platforms, emerged. These now function as dominant content purveyors and major speech platforms that

2 The On-Line Copyright Infringement Liability Limitation Act (OCILLA) commonly known as $\S 512$ of the DMCA — is codified as Title II of the DMCA at 17 U.S.C. $§ 512$ (2012). Title I of the DMCA — which covers anticircumvention is unrelated.

3 S. ReP. No. 105-190, at 20 (1998); H.R. ReP. No. 105-551, pt. 2, at 49 (1998). 
have both radically democratized expression and have become competitors of companies in the traditional copyright industries.

For major rightsholders facing large-scale infringement, enforcement has also changed. Often relying on third-party rights enforcement organizations ("REOs") or in-house "content protection" teams, these rightsholders use automated "bots" to search for infringements and automatically generate takedown notices. Automation is necessary in the face of large-scale infringement, but machine-based decisionmaking also raises questions about notice quality and appropriateness. And while large rightsholders can use these methods to manage online infringement, smaller rightsholders without access to them may find it difficult to enforce their copyrights online. ${ }^{4}$

How these changes affect the notice and takedown regime is under studied, as are longstanding questions, including whether the safe harbors operate as intended and to what extent some notice senders may misunderstand or abuse the takedown remedy. Despite the enormous technological changes since the law was passed, ongoing disputes about the efficacy of notice and takedown for policing infringement online, and criticisms of improper takedowns targeting expression online, there is relatively little information about how the system operates in practice and how stakeholders experience it. Because it relies on a series of private notices and actions by private parties, notice and takedown largely operates without public visibility into the practices of rightsholders, OSPs, or alleged infringers. There have been few empirical studies - largely because the relevant data has been hidden from public view and politically sensitive to the parties involved. Reviews by Urban and Quilter (2006), Quilter and Heins (2007), and a recent statistical inquiry into notices by Seng $(2014)^{5}$ largely exhaust the empirical research literature on the topic. ${ }^{6}$

4 See e.g., The Arts and Entertainment Advocacy Clinic at George Mason University School of Law, Response to "Section 512 Study: Notice and Request for Public Comment" (giving four examples of "middle class artist" experiences with notice and takedown).

5 See Jennifer M. Urban \& Laura Quilter, Efficient Process or "Chilling Effects"? Takedown Notices Under Section 512 of the Digital Millennium Copyright Act, 22 Santa Clara Comp. High Tech. L.J. 621 (2006); Laura Quilter \& Marjorie Heins, Brennan Center for Justice, Intellectual Property and Free Speech in the Online World: How Educational Institutions and Other Online Service Providers Are Coping with Cease and Desist Letters and Takedown Notices (2007); Daniel Seng, The State of the Discordant Union: An Empirical Analysis of DMCA Takedown Notices, 18 VA. J.L. \& ТЕCH. 369 (2014).

6 There are also a few recent, but generally narrower empirical reviews of copyright takedown activity. See, e.g., Bruce Boyden, The Failure of the DMCA Notice and Takedown System: A Twentieth Century Solution to a 


\begin{tabular}{lllll}
\hline |ljciprod01 $\backslash$ productn $\backslash \mathrm{C} \backslash \mathrm{CPY} \backslash$ 64-3\CPY303.txt & unknown & Seq: 5 & 28-SEP-17 & 12:42 \\
\hline
\end{tabular}

In recent years, federal agencies have also begun work to consider some of these questions. A 2013 U.S. Department of Commerce task force "green paper" documents stakeholders' experiences addressing online copyright issues, including stakeholders' interaction with notice and takedown under the DMCA. ${ }^{7}$ In 2016, the Copyright Office began a study to evaluate the impact and effectiveness of $\S 512 .{ }^{8}$ Though the Copyright Office has not yet issued its findings, responses to its Notice of Inquiry ${ }^{9}$ shed some light on stakeholders' experiences with notice and takedown.

To further illuminate how the system operates in practice and help fill the gap in empirical studies on the effects of notice and takedown, we undertook three empirical studies, detailed in the report, Notice and Takedown in Everyday Practice: ${ }^{10}$

- A qualitative study that documents the ways in which the notice and takedown process has been perceived and operationalized by U.S. OSPs and large rightsholders, based on confidential surveys and in-depth interviews with nearly three dozen OSPs and notice senders ("Study 1").

- A quantitative examination of a random sample of takedown notices, taken from a set of over 108 million requests submitted to the Lumen $^{11}$ archive over a six-month period (most of which relate to Google Web Search) ("Study 2").

- A further detailed quantitative examination of a random sample of notices that were sent to Google in relation to its Google Image Search service, isolated from the same six-month set of takedown requests taken from the Lumen archive ("Study 3").

In this shorter article, we digest findings and analysis from Study 1 the qualitative study of OSPs and notice senders. We do not cover the quantitative studies here, but refer to them where relevant.

Twenty-First Century Problem (2013), http://cpip.gmu.edu/wp-content/up loads/2013/08/Bruce-Boyden-The-Failure-of-the-DMCA-Notice-and-Takedown-

System1.pdf; Kris Erickson et Al., Copyright And the ECONOMic EfFects of Parody: An Empirical Study of Music Videos on the YouTube Platform AND AN Assessment of the Regulatory Options (2013), https://www.gov.uk/ government/uploads/system/uploads/attachment_data/file/309903/ipresearch-paro dy-report3-150313.pdf.

7 Dep't of Commerce Internet Policy Taskforce, Copyright Policy, Creativity, and Innovation in the Digital Economy (2013).

8 Section 512 Study, Copyright.GOv, https://www.copyright.gov/policy/section512/ (last visited Jan. 10, 2017).

9 Section 512 Study: Notice and Request for Public Comment, 80 Fed. Reg. 81862 (Dec. 31, 2015), https://www.copyright.gov/fedreg/2015/80fr81862.pdf.

10 Notice and Takedown in Everyday Practice, supra note 1.

11 Lumen, https://lumendatabase.org (last visited Jan. 10, 2017). 


\section{SUMMARY OF METHODS 12}

We took a descriptive approach, focusing on the day-to-day experiences and practices of OSPs and major notice senders interacting with the takedown system. The primary data are original and qualitative, drawn from a detailed survey and a set of semi-structured interviews with OSPs and rightsholders.

To develop as broad and accurate a picture of the notice and takedown process as possible, we employed mixed methods in generating our sample of respondents. We began with the center of the notice and takedown regime: the intermediary OSPs. We interviewed twenty-nine OSPs, including platform, connectivity, and search providers. ${ }^{13}$ To this we added interviews with six major notice senders (including rightsholders, trade associations, and REOs). These data were combined with publicly available information and secondary literature and reporting.

We reached the survey and interview group using a multi-layered selective sampling approach. We initially identified OSPs to contact using a list of the top-100 websites in the United States in terms of traffic ${ }^{14}$ and then distributed the survey to these service providers' designated DMCA agents using the list of designated agents on the U.S. Copyright Office website. We then employed a modified snowball approach. Survey recipi-

12 For a complete description of our methodology, as well as the survey and interview questions we used, see Notice AND TAKedown IN Everyday PRACTICE, supra note 1, at 26-28 and App'x B.

13 Respondents included video and music hosting services, search providers, file storage services, e-commerce sites, web hosts, connectivity services, and other user-generated content sites (e.g. blogs, social media, or other specialized platforms). Eleven of our OSP respondents' services were oriented towards individual users (e.g., user-generated content or entertainment services) and eighteen were oriented towards both enterprises and individuals (e.g. cloud software and storage, or productivity tools). Fifteen were small companies with fewer than 100 employees, six were medium companies with 100-499 employees, and eight were large companies with 500 or more employees.

14 Top Sites in the United States, ALEXA, http://www.alexa.com/topsites/countries/ US (last visited Feb. 5, 2016). Using the top-100 websites both limited researcher bias and ensured that initial respondents were likely to have sufficient traffic to engage with the notice and takedown process. Of the 100 emails sent to DMCA agents using the contact information provided on the list of designated agents on the U.S. Copyright website, eighteen of these emails failed to deliver (generating automated server error response). We expect that future researchers may run into fewer bouncebacks. Effective December 1, 2016, the U.S. Copyright Office issued an update to 37 CFR Part 201 to address the fact that "much of the information currently contained in the directory [of DMCA agents] has become inaccurate and out of date." The new rules require OPS to register a DMCA agent through an electornic filing with the Copyright Office and to renew its registration every three years. 37 CFR $\$ 201.38$ (c) (electronic registration requirement); 37 CFR $\S 201.38(c)(4)$ (periodic renewal requirement). 


\begin{tabular}{lllll}
\hline |ljciprod01 $\mid$ productn $\backslash \mathrm{C} \backslash \mathrm{CPY} \backslash$ 64-3\CPY303.txt & unknown & Seq: 7 & 28-SEP-17 & 12:42 \\
\hline
\end{tabular}

ents were encouraged to forward the survey to other potential respondents. The widely broadcast survey led to interviews, and interview respondents recommended other respondents. In order to maximize our chances of covering typical cases, we also approached OSPs who clearly represented a category or size of service not represented in our initial outreach. ${ }^{15}$ With regard to notice senders, we focused on supplementary interviews with large rightsholders with strong interests in the operation of notice and takedown and their representatives. ${ }^{16}$ Some of the initial set of service providers and rightsholders then forwarded our request on to other potential participants. We took care to solicit participation from a wide range of stakeholders who were diverse in size, type of service, and position within the ecosystem. The result is not a statistically representative sample of the OSP or rightsholder communities, but it is a broadly inclusive one with more than one representative of nearly all of the major categories of service, as well as important differentiators within those categories.

We accepted no limitations on our reporting. No respondent reviewed our report prior to publication, except for a very small number of brief excerpts provided by us to request permission to quote a source without aggregating and anonymizing.

The study has a number of limitations. Because of the sensitivity of many of these issues, our respondents overwhelmingly required assurances of confidentiality prior to participating in surveys or interviews. Many OSPs hesitated to publicly reveal notice-handling practices due to the history of litigation in this area - in some cases based on concerns that they might attract the attention of third-party REOs. Rightsholders were concerned that revealing detailed information about specific enforcement practices could complicate their enforcement efforts or undermine competitive advantages. Because of these concerns, data from the surveys and interviews are anonymized or reported in general terms only, except where we requested and received permission to report in greater detail. Other findings draw on publicly available information and data. As such, we stress that when reported experiences or descriptions identify an OSP or sender by name, this is not an indication that the identified example was a respondent.

Even with confidentiality protections in place, a significant number of OSPs and senders were reluctant to reveal some information about their practices. This limited both the number of respondents and the data we gathered. Most notably, it tended to affect the level of detail that some

15 See supra note 13 for the range of OSPs included.

16 These included trade associations, large organizational rightsholders, and REOs. They represented a range of the industry sectors that most use notice and takedown: games, movies, music, software, and the like. 
respondents felt that they could reveal. Some OSPs were not comfortable filling out the survey or speaking to us at all. ${ }^{17}$ In order to maintain confidentiality under these circumstances, the resulting narrative is at times very specific with regard to stakeholders and other times remains at the level of generalizations and categories.

The study is also limited by the fact that we could not fully cover all stakeholders. We did not survey or interview targets of notices (those who are alleged to directly infringe), limiting our ability to report on this important stakeholder group; we did, however, ask our respondents about their interactions with targets. Both the OSPs and the senders, including REOs, with which we spoke tended to be professionalized, and all were reputable in their industries. Our respondent pool did not include representatives of so-called "notorious" file sharing sites, nor did it include obviously abusive senders. The senders with which we spoke tended to be or represent large copyright owners with valuable properties, limiting our ability to comment on the interests of smaller copyright holders; we did, however, ask our OSP respondents about smaller senders. We did not speak with rightsholders from the adult entertainment industry or their agents, a group that our respondents agreed are particularly prolific and aggressive users of the takedown system.

\section{OSP AND RIGHTSHOLDER ACCOUNTS OF NOTICE AND TAKEDOWN PRACTICE}

Our goals for this qualitative study were primarily descriptive: we sought to understand the "nuts and bolts" of daily notice and takedown practice, potential effects of the safe harbors and takedown requirements, and the successes and challenges our respondents experienced with the system. In this paper, we cover some of the main observations. We invite readers to review the full report for further information. ${ }^{18}$

\section{A. "Woven Into the Fabric" of the Internet}

One of the threshold questions for the study was whether notice and takedown is still relevant to online services, given how much they - and the practice of infringement - have evolved since 1998. The answer to this question is a resounding "yes." Our respondents described notice and

17 There is also the possibility that respondents were not fully forthcoming or provided information with "spin" in their favor. Providing confidentiality helped limit this risk. Further, because most respondents revealed information that challenged public narratives around notice and takedown, including narratives that functioned in their interest, we think this problem was limited. There were occasional instances of respondents apparently repeating "talking points." These we discounted unless supported from other sources.

18 Notice and Takedown in Everyday Practice, supra note 1, at 25-75. 
\begin{tabular}{lllll}
\hline |ljciprod01 $\mid$ productn $\backslash \mathrm{C} \backslash \mathrm{CPY} \backslash$ 64-3\CPY303.txt & unknown & Seq: 9 & 28-SEP-17 & 12:42 \\
\hline
\end{tabular}

Notice and Takedown

379

takedown - and especially the compromises it strikes regarding OSP liability for copyright infringement - as constitutive of rightsholder and OSP responses to online infringement. Though different players experience notice and takedown in different ways, it remains foundational to how both OSPs and notice senders address copyright infringement and negotiate duties under the law. All respondents agreed that the provisions are, as one put it, "woven into the fabric" of the policies, practices, and physical infrastructure that OSPs and rightsholders have built to manage online infringement.

OSPs and notice senders diverged, however, regarding how successful $\S 512$ is in everyday practice. OSPs valued its liability protections, which remain central to OSPs' sense of their freedom to operate. OSPs described the ability to take down infringing material and to remain protected from their users' infringements as fundamental to their survival in an environment in which high statutory penalties for copyright infringement could easily sink companies. As one OSP described it, OSPs "live or die" by $\S 512$ 's safe harbors. As another put it, the DMCA takedown regime was a "godsend," allowing OSPs to operate in an increasingly complex online ecosystem in which connectivity services, platforms for content distribution and speech, search engines, and other services have widely differing relationships with their users and user infringement. OSPs' complaints, discussed further below, centered on the perceived risk of ignoring inaccurate or improper notices and, for some OSPs, fears that vastly increased notice-sending or shifts to filtering or similar requirements could outpace their resources, undermine their relationships with their users, and ultimately impinge on their freedom to operate.

Rightsholders gave more mixed verdicts. They agreed that notice and takedown is fundamental and considered it central to their enforcement strategies, but also uniformly described it as inadequate to fully address large-scale online infringement. Rather, they described notice and takedown as one core tool within a set of tools they use to address infringement, including user education, strategic lawsuits, and other methods.

\section{B. Diversity In Practice: "DMCA Classic," "DMCA Auto," and "DMCA Plus"}

While the overall experience of $\S 512$ as foundational was common to all respondents, OSPs and rightsholders' implementations of it showed more variation and nuance than is generally reported. In some cases, practices by different actors were strikingly divergent. The most prominent split occurred between OSPs and senders dealing with large-scale infringement and those able to continue with more traditional practices. Some large rightsholders have responded to Internet-scale infringement by transforming their notice-sending practices, and adopting automated sys- 


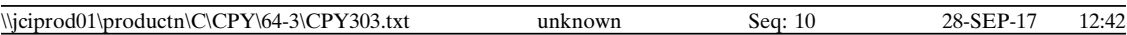

tems to detect infringing content and send takedown notices on a massive scale. These sophisticated players' rapid adoption of automated systems is closely connected to the growing professionalization of large-scale enforcement, characterized by the emergence of specialized "content protection" teams in major trade associations and media companies, and by the growth of the REO sector that sells services to them. ${ }^{19}$ For others, notice and takedown practice remains essentially as it was twenty years ago.

In response, a deep divergence in OSPs' day-to-day experience has appeared over the last decade. As shown in Table 1, OSPs split into three broad groups, which we have termed "DMCA Classic," "DMCA Auto," and "DMCA Plus."20

19 There has been very little research into this newer tier of commercial players, but it is clear that professionalized enforcement is a crucial source of large-scale noticing. Urban and Quilter noted the emergence of REOs sending notices to a Texas ISP between 2004 and 2007. Seng's 2014 review of notices from the Lumen archive traced a further shift toward REO sending. Seng, supra note 5, at 396. Between 2008 and 2012, Seng found that REOs issued between $37 \%$ and $60 \%$ of notices sent to Google annually. Id. Of the top twenty takedown request submitters to Google Web Search in 2015, thirteen were REOs, four were record, film, or software trade associations, and three were individual studios. Transparency Report, Google, http://www.google.com/transparencyreport/removals/copyright/?hl =en (last updated Jan. 9, 2017) (see the Reporting Organizations subsection for most recent data). Our interviews with OSPs broadly confirmed this. Those OSPs that received large-scale, automated notices described them as emanating from professionalized enforcement groups. Notice AND TAKeDOWN IN EVERYDAY PRACTICE, supra note 1, at IV.B.1.a.

20 See also Annemarie Bridy, Copyright's Digital Deputies: DMCA-Plus Enforcement by Internet Intermediaries, in RESEARCH HANDBOOK ON ElECTRONIC COMMERCE LAW (John A. Rothchild ed., 2016), http://ssrn.com/abstract=2628827 (distinguishing two categories of DMCA-Plus enforcement practices: Type 1 DMCA-Plus entities, which operate under the DMCA, but have adopted measures not required by the DMCA (generally corresponding to DMCA Plus OSPs in our analysis); and Type 2 DMCA-Plus entities, which would not generally attract secondary liability under U.S. law and do not operate under the DMCA statutory regime, but which have adopted measures beyond those required to obtain the safe harbor (generally corresponding to Para DMCA OSPs in our analysis)). 


\begin{tabular}{lllll}
\hline |ljciprod01 $\mid$ productn $\backslash \mathrm{C} \backslash \mathrm{CPY} \backslash$ 64-3\CPY303.txt & unknown & Seq: 11 & 28-SEP-17 & 12:42 \\
\hline
\end{tabular}

Notice and Takedown

\begin{tabular}{|c|c|c|}
\hline DMCA CLASSIC & DMCA AUTO & DMCA PLUS \\
\hline \multicolumn{2}{|c|}{ Within DMCA secondary liability framework } & Beyond DMCA Requirements \\
\hline \multirow[b]{2}{*}{$\begin{array}{l}\text { - OSPs receive relatively few notices } \\
\text { - OSPs engage in substantive human } \\
\text { review of notices and respond to } \\
\text { takedown requests with varying } \\
\text { degrees of risk tolerance } \\
\text { - In many cases, OSPs' practices } \\
\text { and concerns are not well. } \\
\text { reflected in policy discussions }\end{array}$} & \multicolumn{2}{|c|}{$\begin{array}{l}\text { - OSPs receive large numbers of automated notices, or feel vulnerable to a } \\
\text { potentially large influx of notices or other forms of rightsholder pressure } \\
\text { - OSPs develop systems to triage notices (taking down } \\
\text { content with little or no substantive human review) }\end{array}$} \\
\hline & $\begin{array}{l}\text { - OSPs develop automated } \\
\text { systems to process notices } \\
\text { - OSPs facilitate bulk sending } \\
\text { and/or may prioritize processing } \\
\text { of notices by developing } \\
\text { "trusted" sender programs }\end{array}$ & $\begin{array}{l}\text { - OSPs may give senders backend } \\
\text { access with direct takedown privileges } \\
\text { - OSPs may manage content by } \\
\text { integrating content filters or hash- } \\
\text { based "staydown" systems } \\
\text { - OSPs and rightsholders may } \\
\text { agree to side deals to supplement } \\
\text { copyright enforcement under the } \\
\text { DMCA framework }\end{array}$ \\
\hline
\end{tabular}

Table 1: Characteristics of DMCA Classic, DMCA Auto, and DMCA Plus OSPs

Perhaps surprisingly, given the considerable attention large-scale infringement and automated systems merit in policy debates over $\S 512$, it appears that traditional "DMCA Classic" notice and takedown continues as the dominant practice for the majority of OSPs. For DMCA Classic OSPs, notice and takedown continues to operate largely as it has since the DMCA took effect, without large-scale notice sending and handling. These OSPs receive relatively small numbers of notices and subject them to review by human teams. DMCA Classic OSPs commonly receive dozens to hundreds of notices annually, with minimal increases year-on-year. For some, the scale is quite small: nine of our twenty-nine OSP respondents reported receiving fewer than 100 takedown notices per year in 2013. ${ }^{21}$ Although we were not able to survey the entire OSP ecosystem to independently quantify its size, DMCA Classic OSPs made up the large

21 Seven of these nine OSPs reported that these notices included fewer than 100 individual takedown requests; the remaining two did not provide the number of takedown requests. Several other OSP respondents either declined to state or could not provide specific numbers, but described falling squarely in this smallscale processing category. Consistent with our findings, the handful of publicly available transparency reports provide examples of OSPs - some with significant web traffic - that receive small numbers of notices, and that report rejection rates that indicate some substantive scrutiny of requests. For example, in 2014, Wikimedia Foundation (home of Wikipedia) reported receiving twenty-one takedown requests (and rejecting 76\%). Requests for Content Alteration \& Takedown, WiKimEDIA, https://transparency.wikimedia.org/content. html (last visited Feb. 5, 2016) (see "DMCA Requests, and How We Responded" subsection for details). Similarly, Reddit reported receiving 176 takedown requests (and rejecting 62\%). Reddit, Reddit Transparency Report, Requests for User Information 
majority of our respondents, including companies with large user bases and high traffic.

The second and third groups comprise OSPs that do receive automated notices. These OSPs have responded by developing systems to manage the large numbers of takedown requests they receive.

"DMCA Auto" OSPs still operate according to their obligations under the statute - responding to takedown requests for specific alleged infringements that already exist on, or are linked to or from, their systems - but on a massive scale. By comparison with DMCA Classic OSPs, DMCA Auto OSPs typically receive tens or hundreds of thousands (in some cases, millions, and in a very few cases, even more ${ }^{22}$ ) of takedown requests ${ }^{23}$ per year, and have experienced steep increases in volume for each of the last several years. To manage the onslaught, DMCA Auto OSPs typically rely on computer algorithms to process notices, sacrificing human review of the vast majority of takedown requests to accomplish takedown more efficiently.

These OSPs described feeling a great deal of pressure to maintain compliance with takedown demands at ever-increasing costs. A few respondents had moved beyond reactive automation to the proactive methods characteristic of the third group: "DMCA Plus" OSPs. ${ }^{24}$ DMCA Plus OSPs have adopted measures not currently required by the DMCA safe harbor regime, such as hash-matching to identify all instances of a work,

AND FOR REMOVAL OF CONTENT (2015), https://www.redditstatic.com/transparency/2014.pdf.

22 In rare cases, OSPs receive more than this, notably Google, which in 2016 alone received more than one billion requests to remove content from its Web Search service. Transparency Report, GoOGLE, http://www.google.com/transparen cyreport/removals/copyright/?hl=en (last updated Jan. 9, 2017). Giganews - a Usenet provider - is another: it blocked access to more than 500 million individual messages for a one-year period between 2012-2013. Perfect 10, Inc. v. Giganews, Inc., No. CV 11-07098-AB SHX, 2014 WL 8628031, at *10 (C.D. Cal. Nov. 14, 2014) ("Indeed, pursuant to such requests [notices that included a Message-ID], Giganews blocked access to more than half-a-billion individual messages between November 6, 2012 and November 6, 2013."). However, based on our research, these examples are outliers in the ecosystem: very few OSPs (among those that disclosed information to us or report publicly) come close to receiving this number of takedown requests.

23 We describe "requests" because counting notices tells only part of the story. Whereas DMCA Classic notices commonly request takedown for single alleged infringements, automated systems can pack hundreds, thousands, or - in some cases - tens of thousands of takedown requests into single submissions. For example, in 2012, Google's 441,370 notices contained over 54 million individual takedown requests. Seng, supra note 5, at 460-61.

24 This category is similar to Bridy's Type 1 DMCA Plus category. See Bridy, supra note 20. We are grateful to Bill Rosenblatt for his useful suggestion to divide automated practices into those that are "reactive" and those that are "proactive." 


\begin{tabular}{lllll}
\hline |ljciprod01 $\mid$ productn $\backslash \mathrm{C} \backslash \mathrm{CPY} \backslash$ 64-3\CPY303.txt & unknown & Seq: 13 & 28-SEP-17 & 12:42 \\
\hline
\end{tabular}

ex-ante filtering systems or "staydown" systems ${ }^{25}$, direct back-end takedown privileges for trusted rightsholders, contractual side agreements with certain rightsholders that set forth additional protections and obligations for both parties, and other supplementary practices.

Because DMCA Auto and DMCA Plus practices were used by a relatively small number of OSPs, this research could not show a clear trend, but it suggests that DMCA Auto tends to "collapse" into DMCA Plus as OSPs attempt to manage very large numbers of takedown requests.

In addition to these three broad groups of OSPs, we also identified a final group comprising service providers that fall beyond the $\S 512$ framework, which are not likely to incur secondary liability for user copyright infringement under U.S. law. ${ }^{26}$ These "Para DMCA" OSPs may include advertising and payment providers, for example. Though we spoke directly only with OSPs that fall under the notice and takedown framework, enforcement efforts increasingly extend to these Para DMCA OSPs, and they often make up part of an enforcement ecosystem within which DMCA OSPs are acting.

It is surprisingly difficult to predict which OSPs fall into which groups. Numerically, the DMCA Auto and DMCA Plus groups together represent a distinct minority of our respondents - only nine of twenty-nine employed any of these enforcement measures. The nine does include some of the dominant Internet services in their respective areas, but other large services do not employ Auto or Plus measures. DMCA Classic OSPs were often, but not always, companies outside of the contested music, video, and search areas. They were sometimes smaller companies, but were just as often large (in terms of staff and/or traffic or user base). And as we discuss further below, OSPs' places within the takedown ecosystem are not immovable. DMCA Classic OSPs varied in their perceptions of stability - some worried about being pushed into DMCA Auto and Plus practices by new floods of notices; others considered their positions more secure.

25 For a little more detail: OSPs may use file hashing to accomplish site-wide takedown of multiple instances of the same work. Ex-ante filtering systems screen content before it is uploaded to a site by, for example, comparing file hashes or using fingerprinting technologies. "Staydown" systems aim to prevent the reappearance of specific content that a rightsholder has previously identified as infringing by using hash matching and/or fingerprinting technologies to block any future attempts to post new copies of the flagged file. We note that these methods overlap and are not always easy to distinguish in practice. For more detail on how our respondents described and used them, see NoticE AND TAKEDOWN IN EvERYDAY PRACTICE, supra note 1 at 55-60.

26 This category is similar to Bridy's Type 2 DMCA Plus category. See Bridy, supra note 20 . 


\section{Everyday Practice: Implementing Notice and Takedown and} Managing Challenges

In the full report, we documented at length many of the processes, decisions, and challenges involved in takedown practice. We refer readers there for details on, for example: repeat infringer and "strike" policies; ${ }^{27}$ transparency reporting:28 DMCA Auto and Plus practices such as "trusted" sender programs and direct takedown privileges; ${ }^{29}$ hash-matching and site-wide removal; $; 0$ filtering; ${ }^{31}$ staydown; ${ }^{32}$ side agreements; ${ }^{33}$ and Para DMCA practices such as site-blocking and "best practices" for tertiary providers. ${ }^{34}$ We covered both the "nuts and bolts" of practice and some of the debates involved. In this shorter article, we digest some of the findings, focusing on some of the challenges faced by our respondents.

\section{Identifying and Removing Infringing Content}

Both OSPs and rightsholders described systems that they intend to efficiently remove infringing content without unacceptable levels of mistakes (though they sometimes disagreed about what should be considered "efficient" removal and what should be considered an "unacceptable" level of mistakes). The major rightsholders and agents with whom we spoke all invested in dedicated content protection teams, contracts with REOs, or both. Reflecting their DMCA Classic or DMCA Auto/Plus status, OSPs required anywhere from less than one full-time position to handle notices to thirty full-time positions. Several large recipients declined to offer details about their staffing, but in line with the predominant DMCA Classic model, the majority reported between one and three fulltime positions, generally as part of teams dealing with wider compliance issues including privacy, user conflicts, trademarks, and other disputes.

Notice handling practices varied widely among OSPs in their particulars, from whether OSPs used automated web-forms to accept notices, to the methods used to triage notices, to how problematic notices were handled. At the same time, OSPs did exhibit consistency in some general practices. Most notably, they consistently described acting conservatively, erring on the side of takedown in order to avoid liability risk. They also reported surprising consistency in the types of requests that they were most comfortable rejecting and the categories of decisions that require the

27 Notice and Takedown in Everyday Practice, supra note 1, at 46-48.

28 Id. at $49-52$.

29 Id. at $54-55$.

$30 \mathrm{Id}$. at $56-57$.

$31 \mathrm{Id}$. at $57-60$.

32 Id. at 60.

$33 I d$. at $60-62$.

$34 \mathrm{Id}$. at $62-64$. 


\begin{tabular}{lllll}
\hline |ljciprod01 $\mid$ productn $\backslash \mathrm{C} \backslash \mathrm{CPY} \backslash$ 64-3\CPY303.txt & unknown & Seq: 15 & 28-SEP-17 & 12:42 \\
\hline
\end{tabular}

Notice and Takedown

385

most resources to address. Within the category of notices that require more review, the cost of reviewing edge cases, the OSPs' tolerance for risk, and the OSPs' stance on the importance of user rights drive takedown decisions.

\section{Avoiding and Managing Flawed Notices}

Both OSPs and rightsholders were attentive to concerns about notices that targeted non-infringing material or otherwise failed to comply with the statute. That is not to say, however, that they believed $\S 512$ provides sufficient tools to address these issues. OSPs, especially, considered § 512's structure insufficient to deter problematic notices or to protect notice targets. Unsurprisingly, OSPs and senders tended to disagree on the question of relative responsibility for evaluating infringements and assessing claims. OSPs described discomfort with both the cost and the substantive judgment associated with assessing the accuracy of takedown requests, and described the counter notice procedure - discussed further below - as inadequate. Senders endorsed and employed "best practices" intended to limit mistakes, but unsurprisingly tended to focus on the difficulties presented by large-scale infringement. They were more likely to consider the counter notice procedure meaningful, if insufficient.

a) Curbing Automation Mistakes: Best Practices and Their Limitations

Rightsholders, DMCA Auto and Plus OSPs, and some DMCA Classic OSPs each confronted issues related to the accuracy of automated systems. A process that relies on machine judgment for infringement detection and readily scales to send millions of notices has the potential to make mistakes on a similarly large scale. Copyright being a famously fact-specific and nuanced area of law, can machines replace human decisionmaking without causing undue harm?

In interviews, rightsholders that employ these systems expressed sensitivity to this issue. They stressed that the automated systems they use employ measures that attempt to narrowly target content and limit mistakes. The techniques described to us were generally relatively simple. For example, rightsholders described limiting the terms used by web crawlers for title- or artist-matching in order to avoid targeting material such as mash-ups, parodies, reviews of music or movies, and other noninfringing or tolerated-use "dolphins" that might be caught in the net.

Consistently, rightsholders also stressed the importance of conducting human cross-checks on automated results to guard against systemic inaccuracies, like targeting previously removed material or non-existent pages, and against collateral damage, like targeting legitimate content by requesting removal of too much of a page or site. Most major senders described 
supplementing their automated systems with limited manual procedures and triggers for manual, human review to reduce the likelihood of misidentifying infringing content.

These measures commonly extended to limiting the types of sites rightsholders ultimately target with automated notices. For example, one sender distinguished between the techniques it uses to manage infringing content on websites that are "trading in copyrighted content" from those that have a "community" character, such as fan sites. This sender described using initial or periodic human review of sites detected by its automated infringement crawler to determine whether they are clearly "dedicated to infringement." Content that is identified by automated systems as infringing receives different treatment depending on how the site is manually classified by the human reviewer. Material on sites considered "dedicated to infringement" receives less scrutiny before a takedown request is sent than does material on "community" sites, which will receive additional review. This sender also conducts periodic reviews to see if a site is changing its behavior and adjusts its response accordingly.

Other rightsholders described similar triage approaches that attempt, on the one hand, to more efficiently flag infringements, and on the other, to avoid alienating user communities and fan bases. Some described using extensive manual review for edge-case uses that they might consider technically infringing but ultimately tolerated, such as fan work.

Like rightsholders that use automated detection systems, DMCA Auto and Plus OSPs described a variety of methods they use to limit mistakes in automated processing. DMCA Auto and DMCA Plus OSPs described some human attention as important to limiting problems with automated decision-making. OSPs described a variety of triaging systems that escalate certain notices for human review, sometimes through several layers of increasingly expert review.

Still, both rightsholders and OSPs acknowledged that in an automated environment, most decisions are made without human intervention by either the sender or the recipient OSP. And automated systems, even if responsibly deployed, have limited capacity to avoid mistakes. Errors can be hard to catch, as resource constraints prevent any substantial human review of the vast majority of automated notices. Some OSP respondents expressed concern that these systems are particularly ill-suited for complex legal decision-making, such as assessments of whether a particular use may be making a fair use of copyrighted content. Sender respondents acknowledged flaws in automated systems, and, as described above, take steps to avoid the misidentification of targeted material, but accepted some inaccuracy as the cost of mass enforcement.

Appropriate use of automated systems can also require weeding out overly aggressive or bad-faith senders. We spoke only with reputable 


\begin{tabular}{lllll}
\hline |ljciprod01 $\mid$ productn $\backslash \mathrm{C} \backslash \mathrm{CPY} \backslash$ 64-3\CPY303.txt & unknown & Seq: 17 & 28-SEP-17 & 12:42 \\
\hline
\end{tabular}

senders in this study, and the notices we reviewed in Study 2 were also, by and large, sent by or on behalf of known, reputable rightsholders targeting file-sharing sites that rightsholders consider "dedicated to infringement." Our respondent senders - including REOs — stressed the importance of reasonable measures for avoiding mistakes. Unfortunately, interviews with OSPs made it clear that the absence of effective liability for bad requests means that there is little external pressure on senders to adopt such measures. Senders, accordingly, vary widely in their behavior and degree of concern for improper takedown. In the worst cases, DMCA Auto and DMCA Plus systems that facilitate bulk notice sending and streamline removal may facilitate bad-faith, abusive practices.

For example, one OSP respondent who had caught the attention of a well-known "copyright troll" described receiving massive numbers of "trash" notices, apparently designed to make it difficult or impossible to respond. While this OSP used automated measures to manage notices, it could not readily address this type of bad-faith activity. The complement to large-scale fusillades is "hiding in plain sight" - if properly formatted, but bad-faith, requests for takedown lurk within the thousands or millions of notices directed at file-sharing, automated systems may be hard-pressed to detect them. Indeed, the same OSP who had caught the attention of the "copyright troll" automatically removed content in response to notices an understandable approach to large numbers of notices that nonetheless leaves this risk in place.

\section{b) Automation Mistakes: Locating Infringing Material}

Whereas both rightsholders and OSPs were concerned with avoiding fair uses or other substantively legitimate materials, threshold identification problems may be the most common issue with automated notices from sophisticated rightsholders. For several OSPs, the most challenging and resource-intensive aspect of takedown was attempting to identify allegedly infringing material based on imprecise location pointers. ${ }^{35}$ Rightsholders may not identify each specific URL or other identifier where a work is found, instead specifying titles, artists, entire search result pages, or similar identifiers. In response to imprecise requests, OSPs described struggling, or finding it impossible, to locate the allegedly infringing material on their sites or to know whether every instantiation of a title, artist, or other identifier on an identified page was truly infringing. In some cases, these requests turned out to be "false positives" that identified material

35 Findings from our quantitative Study 2 supported these issues raised by OSPs in Study 1: $6 \%$ failed to sufficiently identify the allegedly infringed work and $13.3 \%$ failed to sufficiently identify the material alleged to infringe. NoticE AND TAKedown in Everyday Practice, supra note 1, at 93-94. 
that was never on the OSPs' platform or that had been removed some time - in some cases, a year or two - before the notice was sent.

OSPs described other issues, as well. Takedown requests may point to links at several removes from the file in question. Increasingly, both "pirate" and legitimate sites are dynamic, complex assemblages of content drawn from multiple sources, making precise identification of the source difficult for rightsholders and increasing the potential for ripple effects in the event of an imprecise takedown. OSPs described increased difficulties when takedown requests target pages that may also include non-infringing content. Common examples include requests to remove search result pages that may include both infringing and non-infringing content, requests to remove comment threads that may contain an infringing link somewhere in the thread, and requests to remove pages with dynamic content that may no longer contain the material in question. ${ }^{36}$ At the limit, OSPs reported that takedown requests can become de facto takedowns of whole sites, either through the volume of requests or the targeting of toplevel pages. At the furthest extreme, OSPs reported receiving notices for content that was neither on, nor linked to or from, their systems.

Liability concerns push OSPs to invest significant resources in trying to respond to imprecise notices. The DMCA provides some protection to OSPs in this regard - notices that do not identify the specific location of the alleged infringement are not sufficient to confer knowledge on the service provider ${ }^{37}$ - but the high potential cost of legal challenges leads OSPs to try to identify the material when possible. For example, one OSP that receives a large volume of notices reported that, out of fear of failing to remove infringing material, and motivated by the threat of statutory damages, its staff will take "six passes to try to find the [identified content]."

Most OSPs also reported adopting conservative removal approaches, taking down content in order to avoid liability even if it means also removing non-infringing content on the targeted page. On the other hand, some OSPs were able to develop policies that avoid the most sweeping requests. Search service respondents, for example, generally reported that they reject takedown requests targeting home page URLs.

36 We also observed these issues when independently evaluating notices in Study 2. Notice and Takedown in Everyday Practice, supra note 1, at 93-94.

37 See, e.g., Perfect 10, Inc. v. CCBill, LLC, 488 F.3d 1102, 1114 (9th Cir. 2007); UMG Recordings, Inc. v. Veoh Networks, Inc., 665 F. Supp. 2d 1099, 1108-09 (C.D. Cal. 2009), aff'd sub nom., UMG Recordings, Inc. v. Shelter Capital Partners, LLC, 667 F.3d 1022 (9th Cir. 2011), opinion withdrawn and superseded on reh'g, 718 F.3d 1006 (9th Cir. 2013), and aff'd., 718 F.3d 1006 (9th Cir. 2013); Hendrickson v. eBay, Inc., 165 F. Supp. 2d 1082, 1093 (C.D. Cal. 2001). 


\begin{tabular}{lllll}
\hline |ljciprod01 $\mid$ productn $\backslash \mathrm{C} \backslash \mathrm{CPY} \backslash$ 64-3\CPY303.txt & unknown & Seq: 19 & 28-SEP-17 & 12:42 \\
\hline
\end{tabular}

Notice and Takedown

389

\section{Substantive Mistakes and Human-Sent Notices}

Although there is not a perfect split, in OSPs' telling, notices from automated systems targeting large-scale infringement typically exhibited different defects from those sent by individual human senders. Whereas automated notices were more likely to present issues related to the identification of targeted content, individuals' notices tended to present issues with the underlying claim. These perceptions were buttressed by our quantitative studies: the automated notices in Study 2 were more likely to exhibit issues related to imprecise or misidentifications, and the non-automated notices from smaller senders in Study 3 were more likely to present issues with the underlying claim. ${ }^{38}$

Indeed, several OSP respondents observed that the most consistent predictor of a low-quality notice was that it came from a first-time, oneoff, or low-volume sender. OSPs noted that in their experience, these "small senders" were most likely to misunderstand the notice and takedown process, mistake the statutory requirements, or use it for clearly improper purposes. ${ }^{39}$ Nearly every OSP recounted stories of deliberate gaming of the DMCA takedown process, including to harass competitors, to resolve personal disputes, to silence critics, or to threaten the OSP or damage its relationship with its users. And although the proportion of problematic requests varied by type of OSP, every OSP also told stories of takedowns that ignored fair use defenses or that targeted non-infringing material. Several echoed one respondent's view that "many copyright complaints . . . would obviously qualify as fair use; others are complete fabrications to remove content considered undesirable to the filer." OSPs addressed these issues in a variety of ways, for example, by encoding basic statutory requirements in web forms, thus "forcing" those requirements to be met, and by engaging in user education efforts.

\section{Flawed Notices and Risk Aversion}

While all OSPs raised concerns about mistaken or spurious notices, they varied both in the strength of their concerns and the steps they take to identify and address the issue. Notices that are, as one OSP put it, "defective on their face" - before even getting to questions about the

38 See Notice and Takedown in Everyday Practice, supra note 1, Section IV (Studies 2 and 3).

39 Findings from our quantitative Study 3 supported these observations. Google Image Search requests, largely sent by individuals or small businesses, were much more likely to raise a substantive concern: seven out of ten $(70 \%)$ of the Google Image Search requests raised substantive questions about the claim the takedown request was based on. Leaving aside the one sender responsible for more than half the notices (all of which were based on improper subject matter), 36.3\% still raised substantive issues. 
\begin{tabular}{lllll}
\hline |ljciprod01\productn $\backslash \mathrm{C} \backslash \mathrm{CPY} \backslash$ 64-3\CPY303.txt & unknown & Seq: 20 & 28-SEP-17 & $12: 42$ \\
\hline
\end{tabular}

underlying legal claims - are primary targets of OSP triage systems. Nearly all OSP respondents described taking steps to catch notices missing readily verifiable elements of the statutory requirements, for example: a signature; a statement of good faith; a statement that the notice is accurate. Beyond that, OSPs varied widely in their practices. However, most described feeling limited in how far they could practically go in attempting to address improper notices.

One issue is the cost of adjudicating problematic or edge-case notices. Many OSP respondents, regardless of their size, the size of their teams dedicated to reviewing notices, or the number of takedown requests that they receive, described devoting the majority of their notice-processing capacity to a relatively small number of challenging notices: those that required considering the accuracy of the stated claims; possible fair use defenses; possible public domain scenarios; or other judgments about the limits of protected speech and expression. Such processes are resourceintensive; one large OSP respondent reported that a difficult takedown request might be examined by as many as fifteen people before action is taken. One OSP's triage system ends in a biweekly meeting in which highlevel employees decide whether, as the respondent put it, to "bet the company" by deciding not to remove wrongly targeted material. Few OSPs have the staff or expertise to deal with large numbers of boundary cases.

A closely related issue is fear of liability. Most OSPs reported acting conservatively in order to avoid liability, opting to take down targeted content even when they are uncertain about the strength of the underlying claim, rather than "bet[ting] the company" by leaving the content up. In some cases, OSPs simply take substantive claims at face value and remove everything if notices conform to $\S 512$ 's basic requirements. Four of our respondents reported a takedown rate of $100 \%$. OSPs uniformly described their conservatism as a result of necessarily prioritizing avoiding liability over taking risks that might protect expression. As one described it, "the process forces you to try to stay out of making judgment calls [and] to take [takedown requests] at face value." 40

Beyond this basic conservatism, practices and risk tolerance both varied by type of service. In general, user-generated content services with manageable numbers of notices and loyalty-based communities expressed

40 OSPs varied in their sense of what constitutes "conservative" practice, however, and sometimes described quite sophisticated decision making. For example, one OSP hesitates to reject a notice based on a possible fair use defense for fear of leaving itself without the benefit of the safe harbor but nonetheless described a relatively detailed and nuanced handling of notices, explaining that it, for example, denies takedown requests where a sender claims to have copyright in an idea. (Under U.S. copyright law, ideas are not protectable subject matter. 17 U.S.C. $\S$ 102(b) (2012)). 


\begin{tabular}{lllll}
\hline |ljciprod01 $\mid$ productn $\backslash \mathrm{C} \backslash \mathrm{CPY} \backslash$ 64-3\CPY303.txt & unknown & Seq: 21 & 28-SEP-17 & 12:42 \\
\hline
\end{tabular}

Notice and Takedown

391

more willingness to push back on or reject requests. These OSPs tended to emphasize their concerns about the negative effect of mistakenly targeted content on users. Correspondingly, these OSPs expressed more willingness to accept the risk of declining to act on takedown requests, or in some cases, willingness to take the extra step of reaching out to notice senders to ask them to review or rescind the notice. For example, one OSP with a small team that hand-reviews each notice stated that it does not feel judgments about fair use should rest with the OSP. However, this OSP's staff will sometimes contact the sender to explain that the targeted material appears to be a strong candidate for fair use and to request that the sender rescind the request. The OSP explained that it takes the time to engage with senders of borderline notices because it "wants to be a fine upstanding member of the Internet community." It is occasionally successful at persuading the senders to withdraw requests. However, if a sender refuses to withdraw a request, the OSP will remove the item rather than take on liability risk itself.

OSPs also explained that occasionally, a rightsholder may independently elect to rescind the notice and ask the OSP to reinstate the content (usually in response to bad publicity, and typically, when a problematic notice is sent by an overzealous REO). These cases, however, were the exception rather than the rule.

There was almost universal agreement among OSPs that a lack of effective disincentives or remedies for erroneous notices amplifies the problem of mistaken or spurious notices. As one OSP put it: it is "way too easy for spurious takedown notices to be filed," whether by individuals or by large automated systems sending tens or hundreds of thousands of requests. While responsible rightsholders do take precautions to prevent mistakenly targeting content, there are limited legal incentives for them to do so. Some of the major OSPs ask notice senders to evaluate possible fair use or other exceptions when submitting a notice. ${ }^{41}$ Others mention or even require rightsholders to check a box acknowledging § 512(f) liability for knowing material misrepresentation. ${ }^{42}$ The decision in Lenz v. Universal that copyright holders must consider fair use before sending a notice

41 See, e.g., Digital Millennium Copyright Act (DMCA) Notice, Automattic, http://automattic.com/dmca-notice (last visited Feb. 5, 2016); Removing Content from Google, GooGLE, https://support.google.com/legal/troubleshooter/1114905? $\mathrm{hl}=\mathrm{en}$ (last visited Feb. 5, 2016); Notices of Infringement, MicrosofT, https://www .microsoft.com/info/FormForCloud.aspx (last visited Feb. 5, 2016); Copyright Infringement Notification, PINTEREST, http://www.pinterest.com/about/copyright/ dmca (last visited Feb. 5, 2016); Report Copyright Infringement, TwitTER, https:// support.twitter.com/forms/dmca (last visited Feb. 5, 2016).

42 See, e.g., Digital Millennium Copyright Act (DMCA) Notice, Automattic, supra note 41; Notification of Claimed Ingfringement, Dropbox, https://www.drop box.com/copyright_complaint (last visited Feb. 5, 2016); Removing Content from 
lends some legal support to these practices. ${ }^{43}$ However, in other cases, neither the DMCA's requirement that the copyright owner must have a good faith belief that the use of the material is unauthorized nor its prohibitions against material misrepresentations have been held to require robust investigations by rightsholders. ${ }^{44}$ To date, efforts to get rightsholders to evaluate claims before sending function mainly as educational efforts aimed at small senders.

Further, although they could theoretically recover damages against rightsholders who make material misrepresentations under $\S 512(f)$, OSPs generally consider such remedies to be largely out of reach due to the expense and slowness of court cases, the high standard of proof, and the fact that significant cost recovery is unlikely. ${ }^{45}$ In contrast to the statutory penalties for infringement, which can run to $\$ 150,000$ per infringed work, fraudulent or abusive takedown incurs only proven damages. Several OSPs expressed reluctance to pursue such claims, arguing that the standard of proof required for recovery is simply too high to give them suffi-

Google, Google, supra note 41; Notices of Infringement, Microsoft, supra note 41; Report Copyright Infringement, TwITTER, supra note 41.

43 Lenz v. Universal Music Corp., 815 F.3d 1145, 1153 (9th Cir. 2016) (holding that fair use is "authorized by law" and a copyright holder must consider the existence of fair use before sending a takedown notification under $\S 512(\mathrm{c})$ ). However, the court specifically limited this requirement to the sender's subjective belief rather than an objective determination. Id. at 1153-54.

44 One court described the "good faith" standard as a subjective standard that does not require a full investigation to determine the accuracy of the claim. Rossi v. Motion Picture Ass'n of Am., Inc., 391 F.3d 1000, 1003-4 (9th Cir. 2004); see also Tuteur v. Crosley-Corcoran, 961 F. Supp. 2d 333, 343-44 (D. Mass. 2013) ("In enacting the DMCA, Congress did not require that a notice-giver verify that he or she had explored an alleged infringer's possible affirmative defenses prior to acting, only that she affirm a good faith belief that the copyrighted material is being used without her or her agent's permission.").

45 A handful of cases have tested the scope of $\S 512(\mathrm{f})$. See, e.g., Online Policy Grp. v. Diebold, Inc., 337 F. Supp. 2d 1195, 1205 (N.D. Cal. 2004) (holding that Diebold materially misrepresented its claim in violation of $\S 512$ (f), suggesting it sought to use the DMCA "as a sword to suppress publication of embarrassing content rather than as a shield to protect its intellectual property"). Challenges regarding the meaning of "good faith" in sending notices, in contrast, have generally favored the rightsholders. See Rossi v. Motion Picture Ass'n of Am., Inc., 391 F.3d 1000, 1003-04 (9th Cir. 2004) (holding that the "good faith belief" requirement is a subjective standard, and a full investigation into the accuracy of the claim is not required); Tuteur, 961 F. Supp. 2d at 343 ("In enacting the DMCA, Congress did not require that a notice-giver verify that he or she had explored an alleged infringer's possible affirmative defenses prior to acting, only that she affirm a good faith belief that the copyrighted material is being used without her or her agent's permission.") But see Lenz, 815 F.3d at 1153 (holding that fair use is "authorized by law" and a copyright holder must consider the existence of fair use before sending a takedown notification under $\S 512(\mathrm{c}))$. 


\begin{tabular}{lllll}
\hline |ljciprod01 $\mid$ productn $\backslash \mathrm{C} \backslash \mathrm{CPY} \backslash$ 64-3\CPY303.txt & unknown & Seq: 23 & 28-SEP-17 & 12:42 \\
\hline
\end{tabular}

cient expectations of success to justify a suit. Taking down is also much safer than leaving material up, as it eliminates the possibility of suit against the OSP by the copyright holder. In theory, the target could sue the OSP for removing the material, but the target would also have to meet a high standard to recover, meaning that suits from that direction are highly unlikely. One service provider stated that there is "no choice" but to take down content unless the notice is deficient on its face or obviously fraudulent.

\section{Counter Notices: Inadequate and Infrequently Used}

The other structural remedy available to targets of improper notices, the $\S 512(\mathrm{~g})$ "counter notice" process, also appears to do little to protect notice targets. ${ }^{46}$ Where they apply, the counter notice provisions require OSPs to give targets notice of the complaint against them; targets can respond with a counter notice challenging the takedown. By all accounts, however, the actual use of counter notices is extremely infrequent. Only one respondent among both service providers and rightsholders reported receiving more than a handful per year. Many - including some large services handling thousands of notices per year - reported receiving none.

Respondents had a range of explanations for why counter notices are rare. First, the obligation to pass on a complaint does not apply to connectivity providers or to search providers, so counter notices are unlikely to come from users of these services, even though search and connectivity providers often receive large numbers of notices. Second, the liability risk to users gave OSPs pause. Beyond their own liability concerns, some OSPs felt uncomfortable encouraging counter notice use because the strict requirements might expose targets - their users - to liability if they incorrectly sent a counter notice. While OSPs typically inform their users about the procedures for sending counter notices, many do so with considerable ambivalence. Several observed that the typical target of a DMCA complaint has "little or no knowledge of copyright law," and little capacity to make informed estimates of the risks attendant on filing a counter notice, including the risk of copyright liability and the risk of liability for misrepresentation under $\S 512(\mathrm{f})$.

Relatedly, several OSPs expressed concern about doing anything that might encourage users to assert their rights - even when a notice is

46 See 17 U.S.C. $\$ 512(\mathrm{~g})$ (2012). In addition to the counter notice provisions of $\S 512(\mathrm{~g})$, targets also have recourse to the provisions of $\S 512(\mathrm{f})$ which provide liability for damages, including costs and attorney fees, incurred as a result of the service provider relying upon such misrepresentation in removing or disabling access to material. $\S 512(\mathrm{f})$. However, $\$ 512(\mathrm{f})$ has thus far proved weak and unlikely to result in significant recovery. See supra note 45 and accompanying text. 
clearly invalid - because of the power imbalance between senders and users. In one OSP's view, the prospect of sending users up against media company attorneys backed by statutory copyright penalties "eviscerated the whole idea of counter notice." One rightsholder respondent agreed that "there is a real imbalance of power in the event of a lawsuit. You don't want to go up against [a major entertainment company's] lawyers."

To add insult to injury, some truly abusive counter notice senders may not be deterred. Rightsholders we interviewed had encountered a small number of obvious infringers - mostly Russian or Ukrainian pirates who abused the counter notice process from positions of safety outside the jurisdiction of United States courts.

Overall, respondents considered the counter notice process inadequate. While some rightsholders expressed some faith in the process, OSPs mostly considered it a dead letter, and all agreed that it has notable deficiencies.

\section{Targeting Search Services to Make Infringing Material "A Little Bit Harder to Find"}

Search services occupy a slightly odd place in the notice and takedown ecosystem. Links to content hosted elsewhere are generally not infringing in and of themselves. ${ }^{47}$ Yet findings of secondary liability for linking are possible. ${ }^{48}$ Section 512 accordingly provides a notice and takedown process for "information location" tools such as search engines that

47 Hyperlinking does not itself constitute direct copyright infringement because there is no copying. See, e.g., Online Policy Grp. v. Diebold, Inc., 337 F. Supp. 2d 1195, 1202 (N.D. Cal. 2004); Ticketmaster Corp. v. Tickets.com, Inc., No. CV 997654 HLH(BQRX), 2000 WL 525390, at *2 (C.D. Cal. Mar. 27, 2000); see also Perfect 10, Inc. v. Amazon.com, Inc., 508 F.3d 1146, 1161 (9th Cir. 2007) (holding that providing HTML instructions that direct a user's browser to a website housing copyrighted images "does not constitute direct infringement of the copyright owner's display rights" because "[p]roviding HTML instructions is not equivalent to showing a copy"); Pearson Educ., Inc. v. Ishayev, 963 F. Supp. 2d 239, 251 (S.D.N.Y. 2013) (stating that because hyperlinks do not contain the copyrighted content, forwarding them does not directly infringe on a copyright owner's exclusive rights).

48 Although hyperlinking per se does not constitute direct copyright infringement, "in some instances there may be a tenable claim of contributory or vicarious liability." Diebold, 337 F. Supp. 2d at 1202 n.12. Contributory copyright infringement occurs by "intentionally inducing or encouraging direct infringement" of a copyrighted work. Metro-Goldwyn-Mayer Studios, Inc. v. Grokster, Ltd., 545 U.S. 913, 914 (2005). In Intellectual Reserve, Inc. v. Utah Lighthouse Ministry, Inc., the court granted a preliminary injunction holding that the plaintiff was likely to succeed on the merits of the case for contributory infringement. 75 F. Supp. 2d 1290, 1295 (D. Utah 1999). The court held that the defendant in the case actively encouraged infringement of the plaintiff's copyright when, after being ordered to remove the content from its website, it posted links to three websites containing the 


\begin{tabular}{lllll}
\hline |ljciprod01 $\mid$ productn $\backslash \mathrm{C} \backslash \mathrm{CPY} \backslash$ 64-3\CPY303.txt & unknown & Seq: 25 & 28-SEP-17 & 12:42 \\
\hline
\end{tabular}

affords them safe harbor protection. Indeed, we found that search engines play a unique, and important, role in today's online enforcement efforts.

Although the DMCA anticipated that information location services might play an important role in copyright enforcement, the notice and takedown process barely touched them for a decade. Prior to 2009, Google Web Search received, at most, a few hundred requests per year, and more often a few dozen. A few years later that number was in the hundreds of millions. ${ }^{49}$ Rightsholders had begun to prioritize the role of search in the discovery of infringing content, and automation had given them a means of exercising their rights on a scale commensurate with the indexing function of the major search engines. Rightsholder attention shifted accordingly. As Motion Picture Association of America Chairman Chris Dodd put it in 2013, search engines "bear responsibility for introducing people to infringing content, even people who aren't actively looking for it." 50

Search is potentially an important target for rightsholders, especially for wide-scale infringement: if infringing material is less discoverable, then rightsholders may be more successful in stemming the tide than with notices to hosts. Search providers, however, argued that they were poor targets for addressing piracy, because users do not rely on their services to find infringing content to any great degree. Several senders also acknowledged that search does not produce a significant amount of traffic to the most popular pirate sites. They recognized that consumers locate pirate sites in a variety of ways, and that those who want to reach unauthorized files often travel to the source directly or find them through channels other than traditional search services.

plaintiff's content and actively encouraged the downloading, copying, and posting of the material on other websites. Id. at 1294-95.

49 In 2009, Google received 4,275 notices. Seng, supra note 5, at 444. In 2012, it received 441,370 notices that contained over 54 million individual takedown requests. Id. at 460-61. In 2013, the company processed over 230 million takedown requests. Hearing on Section 512 of Title 17 before the H. Judiciary Subcomm. on Courts, Intellectual Prop., \& the Internet, 113th Cong. 47 (2014) [hereinafter Hearing on Section 512 of Title 17] (testimony of Katherine Oyama, Senior Copyright Policy Counsel, Google Inc.). In 2014, it processed 345 million. Joe Mullin, Google Handled 345 Million Copyright Takedowns in 2014, Ars TeCHNICA (Jan. 6, 2015, 1:05 PM), http://arstechnica.com/tech-policy/2015/01/google-handled-345-million-copyright-takedowns-in-2014. In early 2016, Google was receiving between 17 and 21 million requests $a$ week for its Web Search service. Transparency Report, GoOGLe, supra note 19.

50 Ted Johnson, Showbiz Lobby Puts Capitol Hill Pressure on Google to Take Action on Piracy, VARIETy (Sept. 18, 2003, 9:58 AM), http://variety.com/2013/digital/news/google-pressured-by-hollywood-to-do-more-to-fight-piracy-1200616306/ (quoting Dodd). 
Given these practical limitations, the efficacy of search engine enforcement for rightsholders is measured not by specific takedowns, but by the relative ease of availability of infringing materials. Most rightsholders emphasized their desire for search services to take a more proactive role in reducing the occurrence of links to infringing content - for example, by "de-prioritizing" or delisting troublesome sites. As one rightsholder put it, "If you type in a title and within the first page can find illegitimate content, there is still a problem." How such content is kept off the first page of search returns is viewed as less important: "whether accomplished by de-prioritizing or delisting; that's an academic debate, really." The automated notice and takedown process, in this context, serves mostly to push pirate sites down in rank so that they no longer appear in the first pages of search returns.

Rightsholders were candid about the limits of this approach. One said that, in an ideal world, infringing sites would be completely removed from the search engine index, but in practice the rightsholder hopes that targeting the sites with notices will prompt search engines to push them down so they no longer appear in the first two pages of search returns. This can work because some search providers factor the number of takedown notices they receive for a site into their search ranking algorithms, demoting sites that are the targets of notices. One rightsholder explained that the possibility of site demotion is an important part of its calculus as it decides which sites to target - if a site has a low ranking to start with, but starts to move higher up in a provider's search index, it will start sending notices targeting that site to the search provider. However, this same rightsholder said that if a site is already "hugely popular" and shows up high in the index, notice sending does not seem to demote that site's ranking. This was echoed by another rightsholder, who also said that strategies of sending notices to search targeting sites that are "major indexes for pirated content" had no effect on those sites' rankings. One rightsholder respondent noted that it had abandoned mass sending of notices to search in favor of narrower approaches that exploit "weaknesses" in the pirate ecosystem - such as the less frequent search indexing and lower community resilience of many non-English-language, small community sites.

Following this approach, the major rightsholders have pushed search services to provide other measures to make finding unauthorized file sharing sites more difficult, including: search term filtering, blocking auto-complete for designated terms, rating systems for "good" and "bad" sites, and - at the limit - blocking sites entirely from search results.

Search services generally described being protective of their indexing and search algorithms, which they viewed as part of the infrastructure of the open Internet. Accordingly, they were reluctant to accede to some changes. As in other areas, however, there is room for negotiation. One 


\begin{tabular}{lllll}
\hline |ljciprod01 $\mid$ productn $\backslash \mathrm{C} \backslash \mathrm{CPY} \backslash$ 64-3\CPY303.txt & unknown & Seq: 27 & 28-SEP-17 & 12:42 \\
\hline
\end{tabular}

search respondent described his company's history of experimentation with "reasonable and effective" measures beyond notice and takedown, but viewed most of the strategies proposed by rightsholders as ineffective, and therefore certain to be followed by more demands if adopted. Others reach other conclusions. Google, for example, has adopted autocomplete restrictions ${ }^{51}$ and search result demotion based on the number of takedown notices a site receives. 52

Despite the limitations, rightsholders considered sending takedown notices to search services to be one useful tactic in a broader strategy. Though rightsholders generally agreed that targeting search results is, as one put it, not a "silver bullet," all considered it important. Search is seen as an important target at crucial times, such as just before or just after the release of new entertainment properties. Moreover, several senders described sending notices to the hosting site and to Google Web Search in parallel. (Other search providers also receive notices as part of this strategy, but Google Web Search came up most often in conversations with rightsholders, and other search providers reported receiving fewer requests than the number shown in Google's Transparency Report.)

In the end, rightsholders described sending notices to search providers as a part of an attempt to "attack piracy from all directions," and explained that targeting search is a part of their overall strategy to, at a minimum, make infringing content "a little bit harder to find."

\section{E. Compliance, Competition, and Market Power}

Whereas rightsholders face massively scaled-up infringement since $\S 512$ 's passage, OSPs face both rightsholder demands for efficient enforcement and titanic shifts toward large incumbents in the online service market. Some OSPs fear negative effects on competition and market entry from increased enforcement duties, especially as the marketplace for OSPs now includes a small number of highly dominant OSP incumbents

51 Kent Walker, Making Copyright Work Better Online: A Progress Report, Google Public Policy Blog (Sept. 2, 2011), http://googlepublicpolicy.blogspot .com/2011/09/making-copyright-work-better-online.html (stating that Google filters terms closely associated with infringement from Google Autocomplete).

52 How Google Fights Piracy, Google (2014), https://drive.google.com/file/d/0B wxyRPFduTN2NmdYdGdJQnFTeTA/view (stating that Google factors in the number of valid copyright removal notices it receives for a given site as one signal among hundreds that it takes into account when ranking search results); see also Katherine Oyama, Continued Progress on Fighting Piracy, Google Public PolICY BLOG (Oct. 17, 2014), http://googlepublicpolicy.blogspot.com/2014/10/continued-progress-on-fighting piracy.html (stating that Google refined the signal it uses to downrank sites for which it receives a large number of valid DMCA notices and expects that this will visibly affect the rankings of some of the most notorious sites). 
that can afford high enforcement costs, potentially raising barriers to market entry and competition..$^{53}$

\section{DMCA Classic OSPs Fear Policy or Norm Shifts Towards DMCA Auto and Plus}

The protections Congress granted to OSPs in the "On-Line Copyright Infringement Liability Limitation Act" had a specific purpose: certainty. The contemporary caselaw offered conflicting messages about OSP liability; ${ }^{54}$ reducing this uncertainty was intended to free OSP investment and growth. And as described above, OSPs strongly believe that $\S 512$ 's safe harbors have been successful in meeting this goal; indeed, they give the safe harbors credit for a significant part of their freedom to operate. However, all but the largest OSPs also worry that this success could collapse in the face of policy or practice changes.

Currently, DMCA Classic OSPs receive a manageable number of notices and can process them effectively. For them, takedown works reasonably well, and the safe harbor represents a key protection. But they do not feel complacent. All DMCA Classic OSPs expressed concern that legal or policy changes aimed at resolving debates between DMCA Auto and Plus OSPs and major rightsholders could impose DMCA Auto or Plus requirements that they did not need, could not afford, and - in several cases considered antithetical to their commitment to their users' expressive interests.

Several OSPs also voiced concern that, even in the absence of formal policy or new law, decisions by some high-profile OSPs to implement DMCA Plus measures could set norms that could push DMCA Classic OSPs to follow suit. These respondents were concerned that norm shifting might eventually affect the standards for qualifying for the statutory safe

\footnotetext{
53 Google was a universal reference point for this concern, but other large companies' resources also leave many OSPs far behind; this is especially true of any of the "Big Five" OSPs, which by market capitalization are the largest companies, of any kind, in the world. Natalie Sherman, Are Google, Amazon and Others Getting Too Big?, BBC News (June 8, 2017), http://www.bbc.com/news/business-39875417 (describing the five largest companies worldwide as Apple, Alphabet (Google Inc.'s parent company), Microsoft, Amazon, and Facebook).

54 In the late 1990s, district courts had begun to develop arguably conflicting interpretations of when OSPs could be held secondarily liable for their customers' infringement. Courts in Religious Technology Center v. Netcom, 907 F. Supp. 1361 (N.D. Cal. 1995), and Marobie-FL, Inc. v. National Association of Fire Equipment Distributors, 983 F. Supp. 1167 (N.D. Ill. 1997), did not hold OSPs liable for their users' infringements. But the courts in Playboy Enterprises, Inc. v. Frena, 839 F. Supp. 1552 (M.D. Fl. 1993), and Sega Enterprises, Ltd. v. MAPHIA, No. CIV. A. 93-4262 CW, 1997 WL 337558, (N.D. Cal. June 9, 1997), found bulletin board operators liable for direct copyright infringement, though their users had posted the infringing materials without the board operators' knowledge or control.
} 


\begin{tabular}{lllll}
\hline |ljciprod01 $\mid$ productn $\backslash \mathrm{C} \backslash \mathrm{CPY} \backslash$ 64-3\CPY303.txt & unknown & Seq: 29 & 28-SEP-17 & 12:42 \\
\hline
\end{tabular}

Notice and Takedown

399

harbor. These concerns are exacerbated by the fact that OSPs' places within the takedown ecosystem are not necessarily fixed. Some DMCA Classic OSPs viewed their positions as stable. Others considered their situations more vulnerable, and worried that future deluges of notices could force them to abandon human review and adopt DMCA Auto or Plus measures. They worried that, given the impact of automated systems, they were depending more on the inattention or forbearance of rightsholders and REOs rather than the protection of the law. These OSPs expressed concern that, despite being reputable services with legitimate business models not based on infringement, they, as one put it, had "flown under the radar" of senders' attention. OSPs in this group felt strongly that they were complying with the safe harbor's requirements, but that this was not necessarily enough to preclude either significant increases in the numbers of takedown notices sent to them or pressure from rightsholders to adopt expensive and aggressive automated enforcement systems in the future.

\section{DMCA Plus is Viewed as a Competitive Advantage that Affects Market Entry, Success, and Political Power}

We refer readers to the full study for a more complete discussion of DMCA Auto and Plus approaches, why large rightsholders endorse them, and why OSPs tend to be more skeptical. ${ }^{55}$ But cost is a central OSP concern. Several of the smaller OSPs in our study viewed automation and DMCA Plus enforcement as a source of competitive advantage for larger OSPs, which could better bear the costs of developing and managing these systems and exercise more leverage in negotiations with rightsholders. Smaller OSP players that had been targeted by a large volume of notices for whatever reason described struggling to manage the substantial costs of compliance, giving larger and better-resourced players an advantage.

In some striking cases, it appears that the vulnerability of smaller OSPs to the costs of implementing large-scale notice and takedown systems and adopting expensive DMCA Plus practices can police market entry, success, and competition. Those without sufficient resources to build or license automated systems described being in precarious positions, at risk of being priced out of the market by better-resourced competition if floods of notices or DMCA Plus requirements were to arrive.

Most such conversations with OSPs focused on content filtering. Several described filtering as a major competitive advantage for larger services, which can afford to either license or develop fingerprinting and filtering technologies (or both). None viewed homegrown development of such systems as a viable option. All were familiar with estimates of the

55 Notice and Takedown in Everyday Practice, supra note 1, Section III.D. 
development cost of Google's dominant Content ID system, which begin at $\$ 60$ million. ${ }^{56}$ Commercial fingerprinting and filtering services, such as Audible Magic and Vobile, do not publicly release pricing. But we can guess at the ballpark: ${ }^{57}$ one medium-sized file hosting service reported that its license for Audible Magic filtering cost $\$ 10,000-12,000$ per month in 2011 (though this provider was later able to negotiate a reduced rate based on the amount of content flagged through the system). Another estimated that Audible Magic cost its service roughly $\$ 25,000$ per month. Cost estimates go beyond this: OSPs noted that the licensing fees are just the beginning, with integration, upkeep, and changing demands all requiring investment.

Because of this, larger players' advantage resides not just in the initial cost of DMCA Auto and Plus systems but also in their cumulative costs as demands change. Automated notice handling does not obviate the need for human review. Content-filtering systems do not obviate the need for automated notice handling. Even if they are off-the-shelf, new systems must be integrated into OSPs' existing systems. And rightsholders vary in their requests, pushing OSPs to run parallel systems to manage different enforcement demands. For DMCA Auto and Plus OSPs, notice and takedown can function less as a clear practice that services must implement and more as a legal standard that underlies ongoing negotiations between rightsholders and OSPs about enforcement practices. Accordingly, DMCA Auto and Plus OSPs described regular negotiations with rightsholders over practices, with different rightsholders requesting different practices, and with new requests arriving on a regular basis. This resulted in continual updates to OSP systems and practices. The DMCA Classic OSPs that felt vulnerable tended to understand that DMCA Auto and Plus technologies were not "turnkey" products or one-time costs, and to fear a shift that gives rightsholders leverage to demand that they implement expensive and ongoing changes. ${ }^{58}$

56 Hearing on Section 512 of Title 17, supra note 49, at 49 (testimony of Katherine Oyama, Senior Copyright Policy Counsel, Google, Inc.). Estimates may vary in the types of costs they take into account. One well- informed respondent suggested that the full cost was likely several times higher.

57 We had too little data to develop any complete sense of the market and expect that these numbers are now out of date.

58 Although this did not come up as much in interviews, presumably because we spoke only with larger rightsholders with significant resources, some smaller rightsholders participating in the Copyright Office study also complained that takedown procedures were non-standardized across OSPs. See, e.g., The Arts and Entertainment Advocacy Clinic at George Mason University School of Law, Response to "Section 512 Study: Notice and Request for Public Comment" [on behalf of] at 7 (Each platform has its own process for reporting infringing content ... this 


\begin{tabular}{lllll}
\hline |ljciprod01 $\mid$ productn $\backslash \mathrm{C} \backslash \mathrm{CPY} \backslash$ 64-3\CPY303.txt & unknown & Seq: 31 & 28-SEP-17 & 12:42 \\
\hline
\end{tabular}

Not all of the competitive advantage derives from costs of development or adoption. The perceived market power of incumbents also derives from the breadth of services they control. For example, one video hosting platform respondent explained that Google has a significant competitive advantage because of Content ID's integration with Google's advertising services. The respondent considered Content ID to provide a significant competitive advantage to YouTube because it enables content owners to monetize content that is posted by users and hosted on the platform. This OSP provided examples of video content that is flagged by matching technology - including fan vids, remix videos, and wedding videos that include songs - that are unlikely to be hosted on its site because, unlike YouTube, it does not have a Content ID-like system that allows in-video advertising revenue shares with rightsholders. This OSP speculated that, in the long term, when users seek out a platform to share videos that include copyrighted content - regardless of whether the use is fair or otherwise allowed - they will just use YouTube in order to avoid takedown. As other OSPs cannot come near affording what they expect Content ID to cost, those with audio and visual offerings considered Google to have a profound competitive advantage. Further, challenges for less-well-resourced OSPs can multiply when their attempts to compete may prompt blocking behavior from multiple dominant incumbents. We refer readers to the full paper and the "SoundLocker" 59 case study, which traces a small music OSP's attempts to enter the market and compete under pressure from the Recording Industry Association of America, other rights groups, Audible Magic, and Google's Ad Sense service. ${ }^{60}$

Several OSPs expressed concern about the diverging political interests of small and large OSPs in this environment. One music service OSP noted that for most of the time that DMCA notice and takedown has been in operation, small and large OSPs' interests in protecting the notice and takedown system were aligned. However, as well-resourced players have implemented filtering systems, this provider worried that "we will see a world where [these large incumbents] start to close the gate behind them" and advocate for DMCA Plus measures. OSP interests are diverging, this respondent stated, as the incumbent OSPs' interest shift to align with rightsholders. This OSP felt that if filtering becomes the "law of the land," then the higher costs of entry will undermine entrepreneurialism and small service providers will not be able to compete. These concerns were exac-

means locating the proper method of reporting infringement for each platform, following the process, and submitting a notice.").

59 This is a pseudonym.

60 Notice And Takedown in Everyday Practice, supra note 1, Section III.E.1. 
erbated by the limited market competition for non-bespoke fingerprinting and filtering systems.

These worries are intensified by DMCA Classic OSPs' views of the overall political economy of notice and takedown. Despite their high numbers, DMCA Classic OSPs tend to be less visible in public debates about notice and takedown where large rightsholders struggling with Internetscale infringement and large OSPs managing floods of notices tend to take center stage. They described being left aside in policy debates and news accounts skewed by attention to the relatively few DMCA Plus entities. Accordingly, they are acutely aware that public debates over notice and takedown may leave their interests aside. More than one DMCA Classic OSP respondent lamented that a lack of resources hampered their ability to participate effectively in policy debates, ${ }^{61}$ much less take a position through litigation. They described the political and litigation-based wrangling over the safe harbors with trepidation borne of a concern that a relative few actors' outsized concerns could harm the legal or practical availability of the safe harbor.

\section{DISCUSSION AND RECOMMENDATIONS}

\section{A. Discussion}

The debate around $\S 512$ only grew more heated as we developed and completed our study. At last year's roundtable for the Copyright Office's $\S 512$ study, then-General Counsel of the Copyright Office Jacqueline Charlesworth likened the stark contrast between the participants' positions to Dickens's $A$ Tale of Two Cities. ${ }^{62}$ Comments submitted by stakeholders in response to the Copyright Office's Notice of Inquiry highlight stakeholders' discordant viewpoints. ${ }^{63}$ A submission from organizations in the music industry argued that notice and takedown "has proved an ineffective tool .... something akin to bailing out an ocean with a teaspoon," 64 while another comment quoted a filmmaker as comparing the notice and takedown system to "standing under Niagara Falls with an um-

61 This may be improving. Some OSPs we would class as "DMCA Classic" have taken part in the Department of Commerce Internet Policy Task Force's Multistakeholder Forum on Improving the Operation of the Notice and Takedown System and the U.S. Copyright Office's Section 512 Study. However, they do still appear to be heavily underrepresented compared to their numbers.

62 U.S. Copyright Office Section 512 Study, Public Roundtable Transcript, May 2, 2016, at 8-9.

63 Section 512 Study: Notice and Request for Public Comment, 80 Fed. Reg. 81862 (Dec. 31, 2015), https://www.copyright.gov/fedreg/2015/80fr81862.pdf.

64 American Association of Independent Music et al., Response to "Section 512 Study: Notice and Request for Public Comment" at 3 (Apr. 1, 2016). 


\begin{tabular}{lllll}
\hline |ljciprod01 $\mid$ productn $\backslash \mathrm{C} \backslash \mathrm{CPY} \backslash$ 64-3\CPY303.txt & unknown & Seq: 33 & 28-SEP-17 & 12:42 \\
\hline
\end{tabular}

brella." 65 At the same time, a comment from a group of online service providers noted that "it would be hard to overstate the importance of the safe harbor protections established by Section 512 in the development of online platforms . ..," ${ }^{66}$ while OSP Automattic argued in its comments that without the safe harbors, "democratization [of access to speech] would simply be impossible." ${ }^{7}$ Echoing these sentiments, a comment from Amazon called the DMCA a "durable[ ] and workable framework that has facilitated the unprecedented dissemination and availability of creative works, increased innovation and content creation, and dramatic economic growth." 68 Layered on top of these competing views of $\S 512$ 's merits and demerits were comments representing a third group of stakeholders: Internet users. In response to a campaign launched by digital rights group Fight for the Future, ${ }^{69}$ over 80,000 commenters submitted a template comment that argued that notice and takedown is "too commonly used to censor content that is protected under fair use" and that the DMCA "needs new safeguards to protect against abuse. ..."70 Similarly, the Electronic Frontier Foundation argued that online service providers "have a financial incentive to err on the side of removing content" and that this "encourage[s] abuse on the part of the governments or private litigants seeking to take down materials for censorial, rather than infringement, reasons." 71

The picture of the $\S 512$ regime painted by our research reflects many of these concerns, but also is notably more complex and nuanced. Political debates can obscure one of the clearest themes we observed: the original process set out in $\S 512$ plays a central role in managing copyright online, and it is functioning well in some of its most basic features. OSPs consider its liability protections foundational to the development of today's online

65 The Arts and Entertainment Advocacy Clinic at George Mason University School of Law, Response to "Section 512 Study: Notice and Request for Public Comment" at 11 (quoting Ellen Seidler).

66 Etsy et al., Response to "Section 512 Study: Notice and Request for Public Comment" at 2 (Apr. 1, 2016).

67 Automattic, Inc., Response to "Section 512 Study: Notice and Request for Public Comment" at 1.

68 Id. at 3.

69 Evan Greer, Nearly 100,000 Internet Users Call for Copyright Office to Improve Fair Use and Free Speech Protections in DMCA, FIGHT FOR THE FuturE (Apr. 4, 2016), https://www.fightforthefuture.org/news/2016-04-04-nearly-100000internet-users-call-for-copyright/.

70 See comments marked as "Template Form Comment" at Requests for Public Comments: Digital Millennium Copyright Act Safe Harbor Provisions, RegulATIONS.GOV, https://www.regulations.gov/docketBrowser?rpp=25\&so=DESC\&sb= commentDueDate\&po=0\&D=COLC-2015-0013 (last visited Jan.10, 2017).

71 Electronic Frontier Foundation, Response to "Section 512 Study: Notice and Request for Public Comment" at 4 (Apr. 1, 2016). 
\begin{tabular}{lllll}
\hline |ljciprod01 $\mid$ productn $\backslash \mathrm{C} \backslash \mathrm{CPY} \backslash$ 64-3\CPY303.txt & unknown & Seq: 34 & 28-SEP-17 & 12:42 \\
\hline
\end{tabular}

404 Journal, Copyright Society of the U.S.A.

ecosystem and critical to their freedom to operate, and large rightsholders depend on its notice and takedown system to help them contend with online infringement.

Interest parties' political positions can also obscure the considerable diversity in the system's current operation. It has evolved into a highly complex ecosystem, with different challenges faced by large incumbents and smaller players, by those in the center of the "copyright wars" and those on the edges, and by those playing different roles in the technology and copyright sectors. A large number of our OSP respondents - indeed, the great majority - are simply not a part of the shift to DMCA Auto or DMCA Plus enforcement measures. Outside of the most vociferous debates over infringement, these DMCA Classic OSPs respond to a limited amount of user infringement via manageable numbers of takedown notices. They fear the safe harbor's practical disappearance if soft pressures to adopt expensive DMCA Plus measures such as filtering are hardened, pushing DMCA Classic OSPs away from traditional notice and takedown and into direct competition with much more well-resourced incumbents that employ heavily automated systems. Any reforms to the system must take into account this diversity of interests and avoid harm to the large group of OSPs for which the system is working.

Our research also suggested some problems. First, while the law continues to provide rightsholders with a copyright enforcement alternative that is far cheaper and easier to use than lawsuits, it also shows strain in the face of large-scale, off-shore infringement. Rightsholders expressed great frustration with extra-territorial infringement-focused sites, which are out of the reach of U.S. jurisdiction. Rightsholders attempt to put pressure on these sites by targeting search engines for takedown, and by making efforts to enlist payment providers and advertising networks to "follow the money" and cut back on the profitability of piracy. Automated sending is a means of addressing this more resilient piracy ecosystem, but it is clearly a management tool rather than a comprehensive solution to the problem.

Our respondents also frankly described problems with some notices, which can both increase OSP costs and potentially undermine the due process and speech interests of targets. Misidentified or imprecise notices can create a substantial burden for OSPs and also create the risk that liabilityshy OSPs will remove noninfringing content in a bid to ensure compliance. Notices - especially from less-sophisticated senders - can also exhibit substantive problems with the underlying claims and in some cases be abusive. These complaints were corroborated in the quantitative studies in our full report, with Study 2 illustrating identification problems stemming 


\begin{tabular}{lllll}
\hline |ljciprod01 $\mid$ productn $\backslash \mathrm{C} \backslash \mathrm{CPY} \backslash$ 64-3\CPY303.txt & unknown & Seq: 35 & 28-SEP-17 & 12:42 \\
\hline
\end{tabular}

Notice and Takedown

405

from automation mistakes ${ }^{72}$ and Study 3 illustrating substantive problems in notices from smaller senders. ${ }^{73}$ Finally, OSPs feel unprotected, even from bad-faith senders, because the legal incentives to avoid bad notices like those from the "copyright troll" described above pale in comparison to the legal incentives to remove material and avoid lawsuits.

Leaving aside true bad faith, notice problems split between sophisticated and less-knowledgeable senders. In the first instance, machinebased decision-making appears to require more and better accuracy checks. In the second instance, human fallibility appears to require increasing lay senders' knowledge of when it is appropriate to send a takedown notice, and disincentivizing mistakes and abuse. The types of requests we saw in Study 3 appeared to be poor candidates for automated fixes; efforts to improve efficiency may be better focused on front-end educational efforts directed at senders rather than automated processing. Smaller senders need better information about when takedown notices are appropriate, and incentives to adopt better sending practices. OSPs need good ways to review and manage notices from these types of senders because of the idiosyncratic nature of many of these requests, OSP responses to requests sent by individuals and other small, non-professionalized senders may require more difficult, time-consuming, and individualized consideration.

The findings from our studies also raised issues related to due process at the OSP level. The identification mistakes, substantive problems with claims, and other issues we observed confirm the prescience of Senator Ashcroft's worries, during the drafting of the DMCA, about targets' due process and expression rights. However, the attempted solution - the counter notice and putback process, buttressed by recovery under $\S 512(\mathrm{f})$ - has been repeatedly criticized as insufficient. From our study, it appears that these safeguards for targets have largely failed. Interviews revealed that the counter notice process is rarely used, and has significant structural limitations. In the constant company of liability fears, OSPs lack confidence to reject bad requests. Modest modifications to the statutory penalties for abusing the notice-and-takedown process, discussed below, could help by incentivizing senders to send higher quality notices and by giving OSPs comfort that leaving material up or replacing it in response to a counter notice will not subject the OSP or its users to undue liability risk.

72 Notice And TAKedown in Everyday Practice, supra note 1, Section IV.B. In Study 2, 4.2\% of requests targeted content that clearly did not match the identified infringed work, $6 \%$ failed to sufficiently identify the allegedly infringed work, and $13.3 \%$ failed to sufficiently identify the material alleged to infringe. Id. Section IV.B.2.b. and Section IV.B.2.c.ii.

73 Id. Section IV.C. 


\section{B. Recommendations and Future Research}

We refer readers to the full report for the details on our recommendations. ${ }^{74}$ But based on our results, we caution policymakers considering changes to the notice-and-takedown system to take into account its complexity. Neither OSPs nor senders are monolithic groups. What they need from notice and takedown, and the challenges they face, differ widely depending on how they are situated. Changes to the safe harbor or the notice-and-takedown process that benefit some groups could have negative unintended consequences for others. Specifically, policymakers should avoid changes that would have a disproportionate detrimental impact on OSPs outside the zones of heightened copyright conflict, such as rules or norms that create barriers to market entry or reduce competition in the OSP sector. Our research suggests that any statutory changes should not disturb the core safe harbor, and should preserve its pro-competition effects. Policymakers should also carefully consider the varying needs of different rightsholders, including those with fewer resources or lesssophisticated copyright knowledge. Last but not least, targets' interests should be carefully taken into account, especially as they are unlikely to be present in policy discussions.

Following this analysis, our recommendations for statutory reforms are modest, and largely follow the suggestions of others. Our research was clear that notice and takedown needs better mechanisms for ensuring that an infringement is actually likely before material comes down and stays down, and better due process mechanisms for targets. As such, we recommend statutory changes to better prevent and remedy mistaken or abusive takedown demands. Like counter notice senders, notice senders should declare under penalty of perjury that their substantive claims in a takedown notice are accurate..$^{75}$ This would even out incentives and encourage accurate notices and counter notices. Along the same lines, we suggest reducing $§ 512(\mathrm{f})$ 's standard for targets to recover damages from senders who make bad claims from "knowing material misrepresentations" to "reckless misrepresentations," and providing for meaningful recovery

\footnotetext{
74 Id. Section V.D.

75 See, e.g., Dena Chen, Musetta Durkee, Jared Friend \& Jennifer UrBan, Updating 17 U.S.C. $§ 512$ 's Notice and Takedown Procedures for INnOvators, CReAtors, AND CONSUMERs 14-15 (2011), https://www.law.berkeley .edu/wp-content/uploads/2015/04/cranoticetakedown.pdf. Disclaimer: Public Knowledge's white paper was prepared by Samuelson Law, Technology \& Public Policy students, representing Public Knowledge under Urban's direction. The opinions in the white paper belong to Public Knowledge and not necessarily any author of this report, though, based on our research, we endorse some of them here as well.
} 


\begin{tabular}{lllll}
\hline |ljciprod01 $\mid$ productn $\backslash \mathrm{C} \backslash \mathrm{CPY} \backslash$ 64-3\CPY303.txt & unknown & Seq: 37 & 28-SEP-17 & 12:42 \\
\hline
\end{tabular}

through limited statutory damages for violations of $\S 512(\mathrm{f}) .{ }^{76} \mathrm{~A}$ "reckless mispresentation" standard is still high, and thus should not affect reasonable notice senders, but it would give targets a more usable response to truly bad notices. Finally, we suggest allowing immediate putback in response to a valid counter notice.

We recommend statutory damages reforms. We recommend adopting reforms proposed by the Department of Commerce Internet Policy Task Force, ${ }^{77}$ along with some modest extensions, including: giving courts discretion to depart from the "per infringed work" calculation in cases of non-willful secondary liability for online services; specifying factors in the Copyright Act that courts must consider when assessing statutory damages; and increasing the availability of statutory damages reductions in cases of innocent infringement. ${ }^{78}$ These could alleviate the consequences of OSPs' conservative behavior, which is driven by fear of very high potential liability for their users' infringements, while leaving in place robust remedies for copyright holders.

Beyond these limited measures to even out incentives, we recommend against broader statutory reforms at this time. Because the notice-andtakedown ecosystem is so diverse, and because the practical availability of the safe harbors and the takedown remedy are so important to different types of OSPs and rightsholders, substantial changes could have unintended consequences. We recommend avoiding statutory changes that would expand automated practices without better control against mistake and abuse, or that could unduly raise the cost of compliance for the vast majority DMCA Classic OSPs. DMCA Plus measures like filtering should remain entirely voluntary, as should Para DMCA measures. We are sympathetic to rightsholders' concerns that have led them to argue for such requirements. Large-scale infringement is a serious problem. However, our research also highlighted the fact that DMCA Plus and Para DMCA requirements would ill fit the large number of OSPs for which DMCA

76 For more detail on these recommendations, along with additional recommendations for statutory reform, see Notice AND TAKEDOWn In EvERYdAy PRACTICE, supra note 1, at 127-33.

77 Dep't of Commerce Internet Policy Taskforce, White Paper on Remixes, First Sale, and Statutory Damages 86-99 (2016), https://www .uspto.gov/sites/default/files/documents/copyrightwhitepaper.pdf. For additional recommendations for what courts should and should not do when awarding statutory damages under the current Copyright Act regime, see Pamela Samuelson \& Tara Wheatland, Statutory Damages in Copyright Law: A Remedy in Need of Reform, 51 WM. \& MARY L. REV. 439, 501-09 (2009), http://scholarship.law.wm.edu/ wmlr/vol51/iss $2 / 5$.

78 For more detail on our recommendations related to reform of statutory damages, see Notice And Takedown in Everyday Practice, supra note 1, at 12930 . 
Classic practices remain adequate. Beyond legitimate concerns about how mistakes made by these systems can affect users' expression interests, interventions risk creating unexpected consequences if they do not take into account both the structural investments OSPs and rightsholders have made in response to $\S 512$ and the different experiences and interests of different participants. Changing the safe harbor requirements to include these more expensive measures risks undermining the essential success of notice and takedown in supporting a robust, competitive marketplace for online speech platforms. These are high potential costs, especially as determined pirates are unlikely to respond to beefed-up legal measures, and are likely to route around stronger technical measures - poorly conceived policy changes could be ineffective, yet cause collateral damage.

Though we think statutory changes should be modest, our research suggests that notice-and-takedown could benefit from further improvement in some sectors. To improve practice while recognizing the diversity in the system, we suggest that policymakers encourage, and senders and OSPs adopt, a series of voluntary best practices and educational efforts.

With respect to automation problems, we suggest that senders adopt "best of breed" policies and practices, suggested by the best practices of our rightsholder respondents. First, senders should avoid inadvertently targeting non-infringing content. Good practices include: focusing automated efforts on "rogue" sites identified through human review; going beyond simple filename or URL matching; employing human spot-checks of algorithmic decision making; developing technical and human methods for better identifying allegedly infringing materials; and employing policies and guidelines for enforcement agents and enforcement staff to help them identify fair use and relevant tolerated uses. Similarly, OSPs that use automated measures should engage in crosschecks to reduce overbroad takedowns. For example, we recommend that OSPs: develop automated methods to weed out obviously flawed notices; conduct human spotchecks of automated notices and refine automated methods that flag questionable notices; and escalate questionable notices for human review. ${ }^{79}$

With respect to notices sent by hand, both this study and Study 3 made it clear that some senders - especially those who are less experienced with copyright law or the notice-and-takedown process - need better information in order to avoid sending problematic notices. These senders are more likely to benefit from guidance at the point of sending a notice. Lack of knowledge may be behind some cases of apparent misuse or abuse by these senders - it is not always clear when abuse is inten-

79 For more detail on these recommendations, as well as additional recommendations, see Notice And Takedown in Everyday Practice, supra note 1, at 13436. 


\begin{tabular}{lllll}
\hline |ljciprod01 $\mid$ productn $\backslash \mathrm{C} \backslash \mathrm{CPY} \backslash$ 64-3\CPY303.txt & unknown & Seq: 39 & 28-SEP-17 & 12:42 \\
\hline
\end{tabular}

tional and when it is based on misunderstanding the copyright system. This creates a role for OSPs - and, potentially, for institutional actors to provide senders with educational materials and guidance about appropriate takedown requests, and to provide targets with educational materials and an easy-to-use counter notice function. We also recommend that OSPs engage in additional scrutiny of notices that display features that indicate that the notice is more likely to be problematic (such as a notice from a sender that is an apparent competitor of a target or is from a onetime or new sender), and question or reject notices in appropriate circumstances. ${ }^{80}$

Finally, though our work was able to provide a fairly detailed picture of $\S 512$ in operation, the notice-and-takedown "black box" remains quite dark, overall. The substantial diversity we were able to observe suggests that the need for further research has some urgency. A more detailed discussion is available in the full report, but some important topics for further research include: small rightsholders' experience with the system; targets' experience with the system; further research into the REO sector; economic analyses of enforcement and compliance costs; and deeper sectoral research. More work is needed.

\section{CONCLUSION}

Nearly twenty years on, notice and takedown as enshrined in $\S 512$ of the DMCA is the core mediator of Internet copyright disputes. The overall picture that emerged from our research suggests that $\S 512$ 's fundamental compromise remains vital, even though Internet services and online infringement have both evolved significantly in the years since it was passed. The safe harbor remains a considerable factor in OSPs' ability to enter the market, survive, and develop, and the takedown process remains a linchpin of enforcement.

Our research also showed, however, that notice and takedown is not wholly satisfactory to any party in the chain. As practiced today, it exhibits some notable weaknesses. At the same time, it also exhibits considerable complexity and diversity, making it difficult to enact reforms without creating unintended consequences. For this reason, our suggested improvements focus on voluntary best practices and limited statutory changes designed to avoid unduly disturbing either the core safe harbor or the takedown remedy.

80 For more detail on our recommendations related to human error, including recommendations for improving small senders' access to more sophisticated enforcement methods, see Notice And TAKedown in Everyday Practice, supra note 1 , at 137-40. 
The nuance depicted in our findings can be difficult to find in public debates over intermediary liability and takedown. Accordingly, it may seem quixotic to try to improve notice and takedown when the most prominent voices in the debate focus on ever-escalating wars between robots and pirates, abusive takedowns, and offshore infringement. But notice and takedown's enduring importance to online speech platforms and copyright holders alike show the value in trying. Relatively modest reforms to better balance the interests of targets and senders, coupled with the best of the practices described to us in our research, would help address some of the challenges created by notice and takedown, while leaving in place the inexpensive, rapid remedy it provides to rightsholders. 